\title{
Erratum to: Long-term efficacy and safety of subcutaneous pasireotide in acromegaly: results from an open-ended, multicenter, Phase II extension study
}

\author{
Stephan Petersenn • Andrew J. Farrall • Christophe De Block - Shlomo Melmed • \\ Jochen Schopohl · Philippe Caron · Ross Cuneo • David Kleinberg • \\ Annamaria Colao $\cdot$ Matthieu Ruffin · Karina Hermosillo Reséndiz • \\ Gareth Hughes $\cdot \mathrm{Ke} \mathrm{Hu} \cdot$ Ariel Barkan
}

Published online: 30 May 2013

(C) Springer Science+Business Media New York 2013

\section{Erratum to: Pituitary}

DOI 10.1007/s11102-013-0478-0

The surname of one of the authors, Christophe De Block, has been spelt incorrectly as Block instead of De Block.

The online version of the original article can be found under doi:10.1007/s11102-013-0478-0.

S. Petersenn $(\square)$

ENDOC Center for Endocrine Tumors, Altonaer Str. 59,

20357 Hamburg, Germany

e-mail: stephan.petersenn@endoc-med.de

A. J. Farrall

Brain Research Imaging Centre, Western General Hospital,

University of Edinburgh, Edinburgh, UK

C. De Block

Department of Endocrinology, Diabetology and Metabolism,

Antwerp University Hospital, Antwerp, Belgium

\section{S. Melmed}

Division of Endocrinology and Metabolism, Cedars-Sinai

Medical Center, Los Angeles, CA, USA

J. Schopohl

Medizinische Klinik und Poliklinik IV, Campus Innenstadt,

University of Munich, Munich, Germany

P. Caron

Service d'Endocrinologie, Maladies Métaboliques et Nutrition, Centre Hospitalier Universitaire Larrey, Toulouse, France

\section{R. Cuneo}

Department of Diabetes and Endocrinology, Princess Alexandra

Hospital, Brisbane, Australia

D. Kleinberg

Neuroendocrine Unit, New York University School of Medicine, New York, NY, USA

A. Colao

Dipartimento di Medicina Clinica e Chirurgia, Università

Federico II di Napoli, Naples, Italy

M. Ruffin - G. Hughes

Novartis Pharma AG, Basel, Switzerland

K. Hermosillo Reséndiz · K. Hu

Novartis Pharmaceuticals, East Hanover, NJ, USA

A. Barkan

Pituitary and Neuroendocrine Center, University of Michigan,

Ann Arbor, MI, USA 